\title{
Reevaluation and update on efficacy and safety of neostigmine for reversal of neuromuscular blockade
}

This article was published in the following Dove Press journal:

Therapeutics and Clinical Risk Management

Jie Luo

Shuting Chen

Su Min

Lihua Peng

Department of Anesthesiology, The First Affiliated Hospital of Chongqing Medical University, Chongqing 400016, China

Correspondence: Su Min

Department of Anesthesiology, The First Affiliated Hospital of Chongqing Medical University, No I Youyi Road, Yuzhong

District, Chongqing 400016, China

$\mathrm{Tel} / \mathrm{fax}+862389011068$

Emailms89011068@I63.com

\begin{abstract}
Postoperative residual neuromuscular block is a serious threat which endangers the patient safety. Neostigmine has been the most commonly used anticholinesterase for the pharmacological reversal of neuromuscular blockade. Although newer agents have been introduced recently, neostigmine has some irreplaceable advantages, including broad-spectrum reversal of all nondepolarizing neuromuscular blocking drugs, low cost, and availability of more related data for clinical practice to refer to. Neostigmine is also noticed to have some drawbacks, such as the inability to reverse profound and deep blockade, potential induction of muscle weakness, cardiovascular adverse effects, and so on. Data on the usage of neostigmine in the geriatric and the pediatric population are still insufficient. Some discrepancies are observed in the results from previous studies which need further investigation. However, recent studies offer some renewed information. Regarding both efficacy and safety, the key for successful reversal of neuromuscular blockade is to use neostigmine "appropriately," optimizing the dosage and timing of administration under close monitoring.
\end{abstract}

Keywords: postoperative residual neuromuscular block, neuromuscular reversal, anticholinesterase, postanesthesia care, postoperative complication

\section{Introduction}

According to the report of the Lancet Commission on Global Surgery, Global Surgery 2030 , about $30 \%$ of the global burden of disease can be treated with surgeries. ${ }^{1}$ General anesthesia is a vital component for many major surgeries. Postoperative residual neuromuscular block (PRNB), defined as the train-of-four $(\mathrm{TOF})$ ratio $(\mathrm{TOFR})<0.9$, has remained a problem with general anesthesia for surgeries. When reversal agents were not administered, the incidence of PRNB could be as high as $37 \%-82 \% .^{2-4}$ After the routine use of anticholinesterase reversal agents, a relatively reduced PRNB incidence of $20 \%-40 \%$ at arrival of the postanesthesia care unit (PACU) has been observed. ${ }^{5}$ PRNB is associated with an increased risk of postoperative pneumonia, coma, and mortality, ${ }^{6,7}$ and appropriate antagonism benefits patients. ${ }^{8}$ Anticholinesterases have been the only available agents for neuromuscular reversal during the past six decades before sugammadex was introduced. ${ }^{8}$ Having been clinically used since 1931, neostigmine is the most common antagonist for neuromuscular blockade with the advantages of broad-spectrum reversal of all nondepolarizing neuromuscular blocking drugs (NMBDs), low cost, and availability of more related data for clinical practice to refer to. Although sugammadex has emerged as a strong competitor, the costbenefit analysis results of its routine administration are still considerably uncertain. ${ }^{9-11}$ 
Indeed, benefit of sugammadex in moderate block has not been fully certified; still, its benefit lies in its speed of reversal, intensity of reversal, and most importantly in its ability to reverse deep block, even in the case of failed intuition. This review aims to offer a reevaluation and update of both the clinical efficacy and safety of neostigmine usage for reversal of neuromuscular blockade based on more recent studies.

\section{Pharmacology}

As an anticholinesterase, neostigmine mainly inhibits the breakdown of acetylcholine, increases acetylcholine in the neuromuscular junction, and enhances the availability of acetylcholine to compete with NMBDs. The metabolism of all the three clinically available anticholinesterases (neostigmine, edrophonium, and pyridostigmine) is influenced by renal function, age, body temperature, intraoperative anesthetics used, NMBDs type and administration route, and the acid-alkali condition. ${ }^{8}$ The distribution half-life $\left(\mathrm{T}_{1 / 2 \alpha}\right)$, elimination half-life $\left(\mathrm{T}_{1 / 2 \beta}\right)$, and total plasma clearance of neostigmine are 3.4 minutes, 77 minutes, and $9.1 \mathrm{~mL} / \mathrm{kg} / \mathrm{min}$, respectively. ${ }^{12,13}$ Both the effective duration and efficacy are related to the type of NMBDs, concomitant anesthetics, the neuromuscular reversal target, and the depth of muscular relaxation when neostigmine is administered. A newly designed administration route, transdermal electroporation, of neostigmine elicited equivalent action as the intravenous one. ${ }^{14}$

One of the most noticeable drawback of neostigmine is its inability to reverse profound and deep blockade, which results from a plateau reached when acetylcholinesterase inhibition is near $100 \%$, and the maximal concentration of acetylcholine is achieved with increasing neostigmine dose not parallelly producing an additional effect (ie, the ceiling effect). The blockade reversal duration of neostigmine may be correlated with this effect as well. ${ }^{15}$ Moreover, the potential for neostigmine to rapidly recover is limited as it cannot instantaneously and completely antagonize, and takes 10 minutes to achieve the peak effect. ${ }^{16}$ The muscle weakness caused by neostigmine when administered after a full recovery from neuromuscular blockade may be due to the increased sensitivities of muscles to overloaded acetylcholine and the desensitization of the receptors.

\section{Administration for neuromuscular blockade reversal The necessities of routine usage}

It was not until 1945 that the importance of neuromuscular blockade reversal had been realized. According to the results of a study in 2018, although only a small dose of rocuronium (ED95) was given for tracheal intubation and the anesthesia duration was relatively long (an average of 163 minutes), there were still $21 \%$ patients who had residual paresis at the end of surgery. ${ }^{2}$ PRNB endangers patients' safety, for which the routine administration of antagonists is beneficial for reducing the risk of incomplete neuromuscular recovery. ${ }^{17}$ There is evidence that in the absence of routine reversal, the PRNB incidence and associated complications markedly increased. ${ }^{4,18,19}$ It is recommended that there should be a routine administration of anticholinesterases in all patients who receive intraoperative nondepolarizing NMBDs for diminishing PRNB, unless full recovery is confirmed with quantitative monitoring. ${ }^{17,20,21}$ However, the actual use of reversal agents varies widely with different countries, anesthesia types, and individual physician's preferences, 3,16 and only $18 \%$ of European and 34\% of American anesthesiologists routinely use reverse muscle relaxants. ${ }^{22}$

Some physicians tend to overestimate the adverse effects of anticholinesterases to outweigh the risks caused by PRNB, and caution against the routine administration of anticholinesterases postoperatively. ${ }^{23-26}$ Since the safety of routine administration of neostigmine was reported in 1959 , the routine usage of neostigmine has been a continuing topic. A few studies found that the incidence of residual paralysis did not change with the administration of neostigmine, and neostigmine was associated with an increased incidence of postoperative atelectasis, which questions the potential of neostigmine in improving neuromuscular recovery. ${ }^{27-29}$ However, a recent study in over 11,000 patients indicated that neostigmine could reduce the respiratory complications and 30-day mortality which were associated with NMBDs.The most common caution has been the reduction in TOFR, muscle weakness, and adverse respiratory events when neostigmine is given in the absence of neuromuscular blockade, but a few other studies found that neostigmine administration after nearly full neuromuscular recovery could have no adverse effect and result in no clinically important muscle weakness. ${ }^{30}$ The causes of these above discrepancies between results of different studies include variations in the therapeutic range, appropriate dosing and timing, and some limitations of inconsistent definition of some indices. For example, reintubation was measured within 7 days postoperatively in a study, which could not be attributed to the use of neostigmine. ${ }^{26}$ Therefore, further large-scale prospective studies with comparable designs and controlled factors are required, especially for determining neostigmine's appropriate dosing and timing. ${ }^{31}$

Most anesthesiologists deem that antagonism of neuromuscular blockade is not necessary if fade is absent when 
assessed with a monitor, there is no muscle weakness with clinical examinations or the time interval since administration of the last dose of intermediate-acting NMBDs exceeds 60 minutes. However, there are evidence that the postoperative risks of some patients increased: even 2 or more hours after a two time ED95 dose of intermediate-acting NMBD, the TOFR of $37 \%$ patients was $<0.9 .^{3}$ The causes of underestimated usage of neostigmine in these patients may include insensitivities of the nerve stimulator assessment and evaluation based on the clinical signs for detecting those with TOFRs of $0.4-0.9$, who actually experience a residual neuromuscular blockade. In practice, if a nondepolarizing NMBD was given in a single small dose (one or two times ED95) and/or $>2$ hours had elapsed since the administration, the benefit of neostigmine should be balanced with potential risks cautiously. ${ }^{2}$ In fact, neostigmine may not be capable of preventing residual paralysis if administered incorrectly, and the administration must be guided by, at a minimum, subjective (more preferably, objective) monitoring. . $32^{32}$

\section{Dosing of neostigmine administration}

In the 1940s, neostigmine was reported to be given "seldomly" in doses of up to $5 \mathrm{mg}$ for the reversal of tubocurarine $(0.4 \mathrm{mg} / \mathrm{kg})$ for abdominal surgery. ${ }^{33}$ During the early period, neostigmine was used at a dose of $1.25-2.5 \mathrm{mg}$ per patient, but later in 1979 it was reported that $2.5 \mathrm{mg}$ was not enough. ${ }^{34,35}$ A dose-effect curve was generated demonstrating the dose-dependent effect of neostigmine and the ceiling effect. ${ }^{36}$ It was theoretically proved that the larger the dosage, the faster the effects and more complete the reversal. As compared with $0,0.01$, and $0.02 \mathrm{mg} / \mathrm{kg}$ doses, $0.04 \mathrm{mg} / \mathrm{kg}$ neostigmine was associated with the shortest time to reach a TOFR of 1.0 from 0.5 for the reversal of shallow neuromuscular blockade with rocuronium or cisatracurium. ${ }^{30}$ The administration of $0.02,0.04$, and $0.08 \mathrm{mg} / \mathrm{kg}$ doses of neostigmine for reversal of atracurium at $\mathrm{T} 1$ values of $40 \%-50 \%$ of control resulted in the median recovery times to a TOF $\geq 0.7$ of $4.5,3.0$, and 2.3 minutes, respectively. ${ }^{37}$ A dose of $0.05 \mathrm{mg} / \mathrm{kg}$ neostigmine could reduce the duration of recovery to at least half as compared to the spontaneous recovery duration after rocuronium administration. ${ }^{38}$ In fact, even $0.07 \mathrm{mg} / \mathrm{kg}$ neostigmine could not reliably reverse a residual neuromuscular block of a TOFR of 0.2 within 10 minutes. ${ }^{39}$ Moreover, it was not possible to reach a TOFR of 0.9 within 30 minutes in all patients, regardless of the number of tactile responses presenting at neostigmine $(0.07 \mathrm{mg} / \mathrm{kg})$ administration. ${ }^{15}$ When used at a higher dose of up to $0.08 \mathrm{mg} / \mathrm{kg}$, neostigmine could not bring more benefits, and a second dose after a single dose of $0.07 \mathrm{mg} / \mathrm{kg}$ was not more effective in shortening the reversal duration when administered during deep muscle relaxation. ${ }^{40}$

The exact optimal dosage of neostigmine varies mainly based on the extent of spontaneous recovery at the time of administration, the half-life of the NMBDs used, and the concomitant anesthetics, which are yet to be defined for all levels of neuromuscular block. In a few other studies, there was no difference between 0.035 and $0.05 \mathrm{mg} / \mathrm{kg}$ doses in time to full recovery for $0.5 \mathrm{mg} / \mathrm{kg}$ rocuronium block at T1 of at least $10 \%$. The speed of acceleration of recovery when administered 5 minutes after administration of rocuronium $(0.4 \mathrm{mg} / \mathrm{kg})$ also did not differ between 0.03 and $0.05 \mathrm{mg} / \mathrm{kg}$ neostigmine, and $0.03,0.04$, and $0.055 \mathrm{mg} / \mathrm{kg}$ neostigmine doses demonstrated very similar time course of effect. ${ }^{41,42}$ It was considered that $2.5 \mathrm{mg}$ neostigmine was an unnecessarily large dose to antagonize the effects of atracurium and vecuronium, if $>20 \%$ recovery of $\mathrm{T} 1 / \mathrm{T} 0$ had already occurred when administered. ${ }^{37,43}$ Moreover, in the same situation, $1.25 \mathrm{mg}$ neostigmine was effective as well, and $0.625 \mathrm{mg}$ accelerated recovery after atracurium (although not vecuronium).$^{43}$ It was calculated that $0.034 \mathrm{mg} / \mathrm{kg}$ neostigmine was required to recover $95 \%$ of patients from a TOFR of $0.5-0.9$ or higher within 5 minutes. ${ }^{44}$ As little as $0.02 \mathrm{mg} / \mathrm{kg}$ neostigmine could be sufficient for a successful reversal of shallow atracurium block (TOFR of 0.4 ) within 10 minutes, and $0.01 \mathrm{mg} / \mathrm{kg}$ was effective for TOFR of $0.6-0.9 .^{36,45}$

Data also suggested that neostigmine may be used in excessive doses than necessary to antagonize the effects of high-dose NMBDs. ${ }^{46}$ However, neostigmine was associated with a dose-dependent increase in the risk of postoperative respiratory complications, and high doses of neostigmine did not improve respiratory safety. ${ }^{27,47}$ Normal doses of neostigmine may produce muscle weakness in the situation of low degrees of residual neuromuscular blockade (ie, a TOFR >0.4), and evidence demonstrates that neostigmine doses over $0.06 \mathrm{mg} / \mathrm{kg}$ may lead to transient muscular weakness. ${ }^{26,27,47,48}$ Considering the possible muscular weakness when administered for shallow blocks and the dose dependence of its adverse cardiovascular effects, relatively lower dosage of neostigmine may be beneficial when recovery is almost complete. Routine administration of reduced doses of neostigmine $(0.01-0.02 \mathrm{mg} / \mathrm{kg})$ even when no fade was felt after TOF or double-burst stimulation can be beneficial for preventing shallow, but potentially harmful, degrees of residual paralysis. ${ }^{31,32}$ Decreasing the dose of anticholinesterase may reduce adverse effects, and one prudent trend to use neostigmine is with as low a dose as is necessary to produce effective reversal effects and minimize the side effects. ${ }^{41}$ However, based on the lack of compelling evidence 
of the efficacy of neostigmine doses as small as $0.01 \mathrm{mg} / \mathrm{kg}$, the opponent opinion considers that doses of $<0.02 \mathrm{mg} / \mathrm{kg}$ are not recommended for light or minimal block. ${ }^{5}$ TOF monitoring should be used to evaluate the possible need for an additional dose of neostigmine.

The interaction of anesthesia with halogenated agents should be taken into consideration as well. Most inhalational anesthetic agents potentiate neuromuscular block. When $0.07 \mathrm{mg} / \mathrm{kg}$ neostigmine was administered on reappearance of the first tactile TOF response for reversal of rocuronium $(0.60 \mathrm{mg} / \mathrm{kg})$, the median recovery time to a TOFR of 0.9 was longer under sevoflurane anesthesia (28.6 minutes) than propofol anesthesia ( 8.6 minutes). ${ }^{49}$ It was found that neostigmine at doses $\geq 0.02 \mathrm{mg} / \mathrm{kg}$ could offset the potentiating effect of sevoflurane on neuromuscular blockades, and isoflurane was found to offset the decreasing effects on TOFR of neostigmine $(0.02 \mathrm{mg} / \mathrm{kg})$ which was administered when TOFR was 0.88 or 0.92 at 2 or 4 hours after a single dose of vecuronium.

\section{Timing of neostigmine administration}

One concern of timing of neostigmine is that the administration is "too late". It has been held for a long time that if neostigmine is given after full neuromuscular recovery, muscle weakness may be induced theoretically. It was found in a report in 1980 that in addition to $2.5 \mathrm{mg}$ neostigmine administered for antagonism of neuromuscular blockade, the administration of a second dose $(2.5 \mathrm{mg})$ depressed the peak tetanic contraction and reestablished tetanic fade, but this study design does not reflect the current routine clinical practice. ${ }^{23,50}$ Another study reported similar reintroduction of neuromuscular blockade with a second dose of neostigmine (2.5 mg) after the first dose at 1 hour after administration of vecuronium. ${ }^{51}$ A later study also indicated that a second dose of neostigmine $2.5 \mathrm{mg}$ diminished tetanic height and increased tetanic fade after the first dose $(2.5 \mathrm{mg})$ administered for reversal of atracurium-induced neuromuscular blockade, which might adversely affect neuromuscular function. ${ }^{24}$ It was found that some patients (eight in 60) who were given $0.04 \mathrm{mg} / \mathrm{kg}$ neostigmine at 2-4 hours after a single dose of vecuronium $(0.1 \mathrm{mg} / \mathrm{kg})$ had decreased TOFR after the administration, and the TOFR of those patients had recovered to $\geq 0.9$ at the time of reversal, although this effect was short-lived (only 10-20 minutes). ${ }^{24,52}$ After administration of neostigmine $(0.03 \mathrm{mg} / \mathrm{kg})$ after the TOFR recovered to unity $(>1.0)$, upper airway collapsibility was increased and genioglossus muscle activation in response to negative pharyngeal pressure was impaired in healthy volunteers. ${ }^{53,54}$
Anticholinesterase agents produce neuromuscular weakness and tetanic or TOF fade if there was not a previous exposure to NMBDs, and dose-related collapse of upper airway muscles may occur, which can be diminished if NMBDs are present (even in small doses). ${ }^{48,55}$

There have been contrary results from different studies. A study showed that a second dose of neostigmine $(0.07 \mathrm{mg} / \mathrm{kg})$ after the same first dose administered for reversal of vecuronium neither hastened nor prolonged the recovery. ${ }^{40}$ Similarly, a recent study indicated that neostigmine administration after spontaneous recovery to a TOFR of 0.9-1.0 was not associated with clinical evidence of anticholinesterase-induced muscle weakness, and small increases in TOFR were even observed. ${ }^{2}$ The causes which may contribute to these inconsistent results include the differences in NMBDs used, monitoring technology, or measurable indices, whether neostigmine was administrated after the termination of inhalational anesthesia, and so on.

Another concern of timing of neostigmine is that the administration is "too early." There were no advantages in giving neostigmine early when deep blockade was present, even in doses $>0.05 \mathrm{mg} / \mathrm{kg}$, and $0.07 \mathrm{mg} / \mathrm{kg}$ neostigmine would also delay the reversal duration when given during deep muscle relaxation. ${ }^{14,56}$ Comparison of the effects of neostigmine $0.06 \mathrm{mg} / \mathrm{kg}$ administered at different depths of blockade indicated that the total recovery time could not be shortened by early usage of neostigmine and attempted antagonism from intense blockade following atracurium infusion offered no clinical advantages. ${ }^{57}$ The total time to recovery was found to be the same whether neostigmine $(0.07 \mathrm{mg} / \mathrm{kg})$ was administered 15 minutes after vecuronium $(0.1 \mathrm{mg} / \mathrm{kg})$ or it was given when T1 had recovered to $10 \%$ of control. ${ }^{40}$ The median recovery time to a TOFR of 0.9 with $0.07 \mathrm{mg} / \mathrm{kg}$ neostigmine for reversal of rocuronium at a posttetanic count of 1-2 (deep block) was 49 minutes, and similarly situation to reverse vecuronium required a median of 50 minutes. ${ }^{58,59}$ Although $0.07 \mathrm{mg} / \mathrm{kg}$ neostigmine accelerated recovery from deep blockade by 20-25 minutes, the returned neuromuscular function was incomplete and unsatisfactory. 5,60

Rather than increasing the doses of neostigmine which are limited by the ceiling effects, waiting longer for the improvement of spontaneous prereversal recovery may be the key to obtain better effects. ${ }^{32}$ An anticholinesterase is recommended to be administered only after the recovery from neuromuscular blockade is presented (ie, a TOF count $\geq 2$ ), and it was recommended to wait until two twitches were seen before neostigmine administration to reach a TOFR $>0.7$, and four visible twitches to reach a TOFR of 0.9 within $10-15$ minutes. ${ }^{17,61}$ 
Complete recovery (TOFR $>0.9$ ) was achieved only if neostigmine was administered when spontaneous recovery was well underway. ${ }^{14}$ More recently, the recommendation based on a systematic review indicated that the administration of neostigmine should be delayed until an advanced degree of prereversal recovery has occurred (ie, a T1 $>25 \%$ of baseline), or the recovery time would be $>15$ minutes. ${ }^{62}$

Generally, it was indicated that, regarding both the reversal time and total recovery time, the optimum time for neostigmine administration for reversal of atracuriuminduced neuromuscular blockade was when $0<\mathrm{T} 1$ (the first twitch in TOF) $<8 \%$ or when $5<\mathrm{D} 1$ (the first twitch in double-burst stimulation) $<15 \% .{ }^{56}$ It is recommended that reversal of profound or deep neuromuscular block not to be attempted using neostigmine. ${ }^{5}$ It is recommended to initiate neostigmine under neuromuscular monitoring as well. However, a recent retrospective study indicated that neither the doses of neostigmine nor the duration to extubation were affected by the depth of the neuromuscular blockade prior to reversal, exposing discrepancies between existing guidelines and the actual clinical practice. ${ }^{63}$ More evidence are needed if the current concepts of timing of neostigmine administration are to be updated.

\section{Recommendations of dosing and timing of neostigmine administration}

Although the data on dosing and timing of neostigmine administration seem to vary according to the different NMBDs and their doses used, the monitoring of neuromuscular block with electrically stimulating indices (eg, TOF and/or TOFR) can provide an objective and standardized measurement for evaluation and prediction, and the recommendations of dosing and timing of neostigmine administration are mainly based on the data from neuromuscular monitoring. It was recommended that $0.07 \mathrm{mg} / \mathrm{kg}$ can be used when TOF is $1-2$, moderate dosage $(0.04-0.05 \mathrm{mg} / \mathrm{kg})$ can be used when TOF is $3-4$, and lower dosage $(0.02 \mathrm{mg} / \mathrm{kg})$ can be used for shallow blockade when TOF is 4. Another suggestion to diminish the incidence of residual curarization by neostigmine was also based on the level of block measured with neuromuscular monitoring: when TOF count is $0-1$, reversal should be delayed (till TOF count of 2); when TOFR is $<0.4$ or count is $2-3,0.05 \mathrm{mg} / \mathrm{kg}$ neostigmine can be administered; when TOF count is 4 with fade, $0.04 \mathrm{mg} / \mathrm{kg}$ can be used; when TOFR is $0.4-0.9$ or count is 4 without fade, $0.02 \mathrm{mg} / \mathrm{kg}$ can be used; but when TOFR is $\geq 0.9$, no reversal will be necessary. ${ }^{8,20}$ Newer recommendations are as follows: reversal should be delayed when TOF count is $0-1$;
$0.05-0.07 \mathrm{mg} / \mathrm{kg}$ neostigmine can be used when TOF count is $2-4$ (with fade by tactile or visual means, TOFR $<0.4$ ); $0.02-0.03 \mathrm{mg} / \mathrm{kg}$ neostigmine can be used when TOF count is 4 (no tactile or visual fade, TOFR $=0.4-0.9$ ); and reversal will be unnecessary when TOFR is $\geq 0.9 .{ }^{5}$

\section{Prevention of adverse effects}

Generally, neostigmine was found to be associated with serious adverse events in $<1 \%$ of patients. ${ }^{64}$ Potentially induced muscle weakness and cholinergic side effects are the main concerns.

The neostigmine-induced muscle weakness may mainly occur in patients who are administered after full recovery and those administered with large doses who are relatively "overdosed" after nearly full recovery. It has been well accepted that reversal is unnecessary when TOFR is at least 0.9 , and an empiric, routine full dose of $0.07 \mathrm{mg} / \mathrm{kg}$ neostigmine at reversal of light (TOFR of $0.1-0.4$ ) or minimal (TOFR of 0.4-0.9) neuromuscular block is not advised. ${ }^{5}$ The updated results from a study published in 2018 showed that $0.04 \mathrm{mg} / \mathrm{kg}$ neostigmine administered for reversal of TOFR of $0.9-1.0$ was not associated with clinical evidence of anticholinesterase-induced muscle weakness. ${ }^{2}$ Moreover, although $0.03 \mathrm{mg} / \mathrm{kg}$ neostigmine administered after spontaneous recovery to a TOFR of 1.0 induced symptoms of muscle weakness (difficulty swallowing and diplopia) in awake volunteers, there is no evidence to answer the question that whether smaller doses $(\leq 0.03 \mathrm{mg} / \mathrm{kg}$ ) of neostigmine have an effect on airway muscular weakness or residual paralysis if administered at (near) full recovery and whether these doses are associated with adverse clinical outcomes when administered empirically (in the absence of neuromuscular monitoring). ${ }^{5,54}$ Hence, administration with lower doses under close monitoring may help in prevention of the potential-induced weakness in these patients.

One of the most severe subsequence from such muscle weakness is associated with respiratory impairment. Neostigmine has been found to induce muscle weakness and adversely affect respiratory outcomes, and is associated with an increased occurrence of atelectasis, pulmonary edema, desaturations, postoperative pulmonary complication, and longer PACU and hospital stays. ${ }^{26,27,47}$ However, some other studies did not demonstrate any clinical evidence of respiratory muscle weakness in postoperative patients. ${ }^{24,30,65,66}$ Furthermore, it was revealed that postextubation airway obstruction is uncommon after neostigmine is used at a TOFR of $\geq 0.9$, and administration of neostigmine with appropriate 
dosage under close monitoring could decrease and even eliminate the risk of postoperative hypoxemic and pulmonary complications associated with NMBDs. ${ }^{26,47}$ Moreover, it was even found recently that as compared to those given saline, fewer patients administrated with neostigmine after spontaneous recovery to a TOFR of 0.9-1.0 experienced moderate or severe hypoxemia, required stimulation to maintain oxygenation, or needed additional oxygen therapy, although these differences were not statistically significant, which might be due to the unpowered designation of the study to examine the above indices as secondary outcomes. ${ }^{2}$ The association of neostigmine administration with improvement in several symptoms of muscle weakness may be resulting from the neostigmine's reversal effects on preventing residual paresis outweigh its potential muscle weakness-inducing effects in the cohort of patients who were benefitted with neostigmine administration even after recovery at a TOFR of 0.9-1.0.

The cardiovascular side effects of neostigmine as an acetylcholinesterase inhibitor are obvious, especially bradycardia and related arrhythmia, the prevention of which can be achieved with the usage of an additional anticholinergic agent (eg, atropine or glycopyrrolate) prior or concomitantly to attenuate the parasympathomimetic activity at nonmuscular acetylcholine receptors. Glycopyrrolate $(0.5 \mathrm{mg})$ was found superior to atropine $(1 \mathrm{mg})$ in protecting against neostigmine (2.5 mg)-induced bradycardia when administered simultaneously with less tachycardia and cardiac arrhythmias, which is due to its more synchronous effects and time course of action matching that of neostigmine better and better regulation on parasympathetic system, and because it does not cross the blood-brain barrier. ${ }^{67}$

Nausea and vomiting are other concerns. Acetylcholinesterase inhibitors were initially not recommended as they increase the rate of postoperative nausea and vomiting (PONV), and it was noted that the risk of nausea and emesis was greater with larger doses $(>2.5 \mathrm{mg})$ of neostigmine than with smaller doses $(1.5 \mathrm{mg})$ or placebo. ${ }^{68}$ However, the supposed emetic properties have not been supported by evidence from meta-analysis. ${ }^{68-70}$ Omitting neostigmine simply for PONV is unjustified.

\section{Neostigmine for special patients Geriatric patients}

The elderly are at increased risk for PRNB with an incidence of $57.7 \%$ (aged 70-90, being nearly as twice as that of the younger population, aged 18-50, 30\%) and associated adverse outcomes, including increased PACU and hospital stay, more hypoxemic events, airway obstruction, and muscle weakness. ${ }^{71}$ Because of the geriatric physiological changes, including declined renal function, a decrease in the nicotinic acetylcholine receptors concentration at the motor endplate, and the release of acetylcholine from the preterminal axon, most NMBDs' effects are prolonged; meanwhile, the same is observed with neostigmine, which may provide some protection against possible recurarization as its prolonged duration of action may negate the prolonged duration of NMBDs action in the elderly. ${ }^{72,73}$ The time to reach a TOFR of 0.6 from pancuronium neuromuscular block was longer in the elderly ( $11 \pm 10$ vs $5 \pm 4$ minutes in the young), and the same as the duration of action of neostigmine $0.07 \mathrm{mg} / \mathrm{kg}$ to antagonize metocurine (32 minutes in elderly vs 11 minutes in young). ${ }^{72,74}$ The prolonged duration of maximum response to neostigmine may be due to a decrease in extracellular fluid volume and initial volume of distribution, which reflect a greater concentration initially available to act at neuromuscular junction. ${ }^{13,75}$ The concomitant increase in the duration of action of both NMBDs and neostigmine reduces the risk of recurarization.

A study on comparison between elderly and young patients administered neostigmine (with doses based on weight) for the reversal of tubocurarine's effects after elective limb surgery demonstrated that there was no significant difference between the two groups regarding the relationship between TOFR and recovery time, the trends of which were similar. ${ }^{76}$ Another study comparing healthy elderly patients with young adults found that the dose-response relationship of neostigmine for reversal of doxacurium's neuromuscular blockade was not significantly different, and the average estimated dose of neostigmine required to obtain $70 \%$ TOF recovery after 10 minutes was $0.0536 \mathrm{mg} / \mathrm{kg}$ in young patients compared to $0.0416 \mathrm{mg} / \mathrm{kg}$ in elderly (no statistical significance). ${ }^{77}$ Whether there was bias because of the relative small size of this study (11 elderly vs 18 young) needs to be taken into consideration. ${ }^{77}$ Other investigators reported that there was no significant age-related difference in dose requirements of neostigmine (concerning the plasma concentration-response data) in the aged, although the results ignored the effect of spontaneous recovery and were based on the continuous background infusion of the NMBDs, which is not a routine clinical practice. ${ }^{75}$ Surprisingly, in another study, the authors reported that as compared with that of the young group, the dose-response curve for neostigmine in the elderly group was parallel but significantly to the right, which suggested an apparently larger dose requirement in the elderly for obtaining antagonism of vecuronium blockade. ${ }^{78}$ Currently, it is more commonly accepted that dosage adjustments are 
not generally needed in geriatric patients, but neuromuscular monitoring should be lasted longer than younger adults.

One focused consideration for the old patients is the cardiac adverse effects of neostigmine. The incidence of new postoperative cardiac dysrhythmias was $14 \%$ in 21 geriatric patients who had received neostigmine $(4.40 \pm 0.66 \mathrm{mg})$ or pyridostigmine even premixed with glycopyrrolate $(0.88 \pm 0.15 \mathrm{mg})$ for reversal of neuromuscular blockade, but all dysrhythmias occurred in those with preexisting cardiovascular diseases. ${ }^{79}$ Another study on 93 old patients reported that as compared to pyridostigmine, neostigmine was associated with a higher incidence of dysrhythmia in all the studied patients, the subcohort of patients with preexisting cardiovascular diseases and those who received a halogenated anesthetic (five times greater in this subcohort when comparing neostigmine to pyridostigmine). ${ }^{80}$ When compared to that in younger patients, the dosage of anticholinergic agents (glycopyrronium or atropine) given with neostigmine was suggested to be reduced in the patients who were over 65 years old because of the more drastic changes in heart rates, and glycopyrronium might be more beneficial. ${ }^{81}$

Whether the adjustment of dosage of neostigmine and/or anticholinergic agents is needed and what is the optimized combination of them in the geriatric patients are still unclear. Therefore, further studies with high quality and larger sample size are required to reconfirm the efficacy and safety of neostigmine's optimal administration in the aged.

\section{Pediatric patients}

PRNB was frequently observed in the pediatric patients (28.1\%), but more commonly in cases reversed with neostigmine $(37.5 \%)$, which may be due to the difficulties in assessing related indices as compared with adults and the unreliable onset time and effectiveness without objective neuromuscular monitoring in the children. ${ }^{82}$ It was held for a long time that higher doses of neostigmine were needed for appropriate antagonism of long-acting NMBDs in children. ${ }^{83}$ In the 1960 s, large doses of anticholinesterase were used in children than adults to obtain reliable recovery; for example, $0.08 \mathrm{mg} / \mathrm{kg}$ neostigmine was administered to antagonize tubocurarine in neonates. ${ }^{84}$ However, later studies indicated that the dose-response curve for neostigmine used to antagonize residual block from tubocurarine was shifted to the left of that of adults, firstly questioning the belief that larger doses of anticholinesterase were needed in children. ${ }^{85}$ It was found that smaller doses of neostigmine were needed in children than in adults (only half the weight-related dose of adults to produce the same effect) for antagonism of neuromuscular blockade by pancuronium or doxacurium and the TOFR was recovered in 10 minutes. ${ }^{86}$ In the case of reversal of rocuronium $(0.6 \mathrm{mg} / \mathrm{kg})$ blockade, even a much smaller dose of neostigmine $(0.0071 \mathrm{mg} / \mathrm{kg})$ produced the same effect in children aged 2-10 years as 0.0566 $\mathrm{mg} / \mathrm{kg}$ neostigmine in adults, and there was no advantage with neostigmine dosage $>0.02 \mathrm{mg} / \mathrm{kg}$ administered to antagonize $90 \%$ of rocuronium's effect in children. ${ }^{87}$ Recovery from pancuronium-induced blockade after a large dose of neostigmine $(0.071 \mathrm{mg} / \mathrm{kg})$ was more rapid in children than in adults, but increasing the dose of neostigmine $(0.1 \mathrm{mg} / \mathrm{kg}$, as compared to $0.05 \mathrm{mg} / \mathrm{kg}$ ) had no significant effect on the total recovery time but increased the variability in children. ${ }^{88,89}$ When comparing with atropine, glycopyrrolate was found to be as safe and effective in children in a mixture with neostigmine for reversal of neuromuscular blockade, although its advantages were not as marked as had been observed in adults. ${ }^{90}$

It was found that when neostigmine was administered after the first twitch reached $10 \%$ of control, the rate of recovery for vecuronium was dependent on age, which was faster in children than in infants and adults. ${ }^{91}$ It was also found that the recovery from rocuronium-induced blockade was faster in children aged 5-10 years than in children aged $1-4$ years. ${ }^{92}$ As compared with children, young children, or infants, the neonates experienced both the longest spontaneous recovery and reversal recovery of neostigmine $(0.03 \mathrm{mg} / \mathrm{kg})$ for rocuronium. ${ }^{93}$ Further studies on differences between subgroups of children at different age ranges are required.

The differences in neostigmine's effects in children as compared to that in adults cannot be explained only with a pharmacokinetic mechanism. ${ }^{38,85}$ Other contributors to the effect of lower dosage of neostigmine in pediatric patients include the local differences at the neuromuscular junction in children (eg, the number and quantity of nicotinic receptors, amount of acetylcholine reserve, or acetylcholinesterase enzyme activity), a more rapid circulation time and the increased cardiac output speeding the delivery of these agents to the neuromuscular junction and the onset of effect, and more rapid removal of NMBDs from the neuromuscular junction. ${ }^{38,94,95}$ Up till now, there have not been enough sound evidence for confirming both the efficacy and safety of appropriate use of neostigmine to reverse neuromuscular block in pediatric patients, and further studies with more coherent design and measurements are needed. ${ }^{96}$

\section{Acknowledgments}

This work was supported by the China Scholarship Council (CSC No 201608505030), the National Natural Science Foundation of China (Grant No 81201053) and the Science 
and Technology Research Program of Chongqing Municipal Education Commission (Grant No KJQN201800419).

\section{Disclosure}

The authors report no conflicts of interest in this work.

\section{References}

1. Meara JG, Leather AJ, Hagander L, et al. Global Surgery 2030: evidence and solutions for achieving health, welfare, and economic development. Lancet. 2015;386(9993):569-624.

2. Murphy GS, Szokol JW, Avram MJ, et al. Neostigmine administration after spontaneous recovery to a train-of-four ratio of 0.9 to 1.0 : a randomized controlled trial of the effect on neuromuscular and clinical recovery. Anesthesiology. 2018;128(1):27-37.

3. Debaene B, Plaud B, Dilly MP, Donati F. Residual paralysis in the PACU after a single intubating dose of nondepolarizing muscle relaxant with an intermediate duration of action. Anesthesiology. 2003;98(5): 1042-1048.

4. Baillard C, Gehan G, Reboul-Marty J, Larmignat P, Samama CM, Cupa M. Residual curarization in the recovery room after vecuronium. BrJ Anaesth. 2000;84(3):394-395.

5. Brull SJ, Kopman AF. Current status of neuromuscular reversal and monitoring: challenges and opportunities. Anesthesiology. 2017;126(1): 173-190.

6. Arbous MS, Meursing AE, van Kleef JW, et al. Impact of anesthesia management characteristics on severe morbidity and mortality. Anesthesiology. 2005;102(2):257-268.

7. Bulka CM, Terekhov MA, Martin BJ, Dmochowski RR, Hayes RM, Ehrenfeld JM. Nondepolarizing neuromuscular blocking agents, reversal, and risk of postoperative pneumonia. Anesthesiology. 2016;125(4): 647-655.

8. Murphy GS, De Boer HD, Eriksson LI, Miller RD. Reversal (antagonism) of neuromuscular blockade. In: Miller RD, Cohen NH, Eriksson LI, Fleisher LA, Wiener-Kronish JP, Young WL, editors. Miller's Anesthesia. 8th ed. Philadelphia: Elsevier; 2015:995-1027.

9. Vymazal T, Krecmerova M, Bicek V, Lischke R. Feasibility of full and rapid neuromuscular blockade recovery with sugammadex in myasthenia gravis patients undergoing surgery - a series of 117 cases. Ther Clin Risk Manag. 2015;11:1593-1596.

10. Montague J, Halloran C. Reversing non-depolarising muscle relaxants, nausea and residual curarisation. Anaesthesia. 2016;71(4):478.

11. Paton F, Paulden M, Chambers D, et al. Sugammadex compared with neostigmine/glycopyrrolate for routine reversal of neuromuscular block: a systematic review and economic evaluation. Br J Anaesth. 2010; 105(5):558-567.

12. Cronnelly R, Stanski DR, Miller RD, Sheiner LB, Sohn YJ. Renal function and the pharmacokinetics of neostigmine in anesthetized man. Anesthesiology. 1979;51(3):222-226.

13. Morris RB, Cronnelly R, Miller RD, Stanski DR, Fahey MR. Pharmacokinetics of edrophonium and neostigmine when antagonizing d-tubocurarine neuromuscular blockade in man. Anesthesiology. 1981; 54(5):399-402.

14. Berkó S, Szúcs KF, Balázs B, et al. Electroporation-delivered transdermal neostigmine in rats: equivalent action to intravenous administration. Drug Des Devel Ther. 2016;10:1695-1701.

15. Kirkegaard H, Heier T, Caldwell JE. Efficacy of tactile-guided reversal from cisatracurium-induced neuromuscular block. Anesthesiology. 2002;96(1):45-50.

16. Lien CA. Neostigmine: how much is necessary for patients who receive a nondepolarizing neuromuscular blocking agent? Anesthesiology. 2010;112(1):16-18.

17. Brull SJ, Murphy GS. Residual neuromuscular block: lessons unlearned. Part II: methods to reduce the risk of residual weakness. Anesth Analg. 2010;111(1):129-140.
18. Maybauer DM, Geldner G, Blobner M, et al. Incidence and duration of residual paralysis at the end of surgery after multiple administrations of cisatracurium and rocuronium. Anaesthesia. 2007;62(1):12-17.

19. Pietraszewski P, Gaszyński T. Residual neuromuscular block in elderly patients after surgical procedures under general anaesthesia with rocuronium. Anaesthesiol Intensive Ther. 2013;45(2):77-81.

20. Kopman AF, Eikermann M. Antagonism of non-depolarising neuromuscular block: current practice. Anaesthesia. 2009;64(Suppl 1): 22-30.

21. Miller RD, Ward TA. Monitoring and pharmacologic reversal of a nondepolarizing neuromuscular blockade should be routine. Anesth Analg. 2010;111(1):3-5.

22. Naguib M, Kopman AF, Lien CA, Hunter JM, Lopez A, Brull SJ. A survey of current management of neuromuscular block in the United States and Europe. Anesth Analg. 2010;111(1):110-119.

23. Payne JP, Hughes R, Al Azawi S. Neuromuscular blockade by neostigmine in anaesthetized man. Br J Anaesth. 1980;52(1):69-76.

24. Goldhill DR, Wainwright AP, Stuart CS, Flynn PJ. Neostigmine after spontaneous recovery from neuromuscular blockade. Effect on depth of blockade monitored with train-of-four and tetanic stimuli. Anaesthesia. 1989;44(4):293-299.

25. Meyer MJ, Bateman BT, Kurth T, Eikermann M. Neostigmine reversal doesn't improve postoperative respiratory safety. BMJ. 2013;346: f1460.

26. Grosse-Sundrup M, Henneman JP, Sandberg WS, et al. Intermediate acting non-depolarizing neuromuscular blocking agents and risk of postoperative respiratory complications: prospective propensity score matched cohort study. BMJ. 2012;345:e6329.

27. Sasaki N, Meyer MJ, Malviya SA, et al. Effects of neostigmine reversal of nondepolarizing neuromuscular blocking agents on postoperative respiratory outcomes: a prospective study. Anesthesiology. 2014;121(5): 959-968.

28. Fortier LP, McKeen D, Turner K, et al. The RECITE study: a Canadian prospective, multicenter study of the incidence and severity of residual neuromuscular blockade. Anesth Analg. 2015;121(2):366-372.

29. Bronsert MR, Henderson WG, Monk TG, et al. Intermediateacting nondepolarizing neuromuscular blocking agents and risk of postoperative 30-day morbidity and mortality, and long-term survival. Anesth Analg. 2017;124(5):1476-1483.

30. Choi ES, Oh AY, Seo KS, et al. Optimum dose of neostigmine to reverse shallow neuromuscular blockade with rocuronium and cisatracurium. Anaesthesia. 2016;71(4):443-449.

31. Fuchs-Buder T. Neostigmine: timing and dosing in 2016. Anaesth Crit Care Pain Med. 2016;35(4):245-247.

32. Fuchs-Buder T, Nemes R, Schmartz D. Residual neuromuscular blockade: management and impact on postoperative pulmonary outcome. Curr Opin Anaesthesiol. 2016;29(6):662-667.

33. Prescott F, Organe G, Rowbotham S. Tubocurarine chloride as an adjunct to anaesthesia; report on 180 cases. Lancet. 1946;2(6412):80-84.

34. Gray TC, Wilson F. The development and use of muscle relaxants in the United Kingdom. Anesthesiology. 1959;20(4):519-529.

35. Viby-Mogensen J, Jørgensen BC, Ording H. Residual curarization in the recovery room. Anesthesiology. 1979;50(6):539-541.

36. Fuchs-Buder T, Meistelman C, Alla F, Grandjean A, Wuthrich Y, Donati F. Antagonism of low degrees of atracurium-induced neuromuscular blockade: dose-effect relationship for neostigmine. Anesthesiology. 2010;112(1):34-40.

37. Harper NJ, Wallace M, Hall IA. Optimum dose of neostigmine at two levels of atracurium-induced neuromuscular block. Br J Anaesth. 1994; $72(1): 82-85$.

38. Hunter JM. Is it always necessary to antagonize residual neuromuscular block? Do children differ from adults? Br J Anaesth. 1996;77(6): 707-709.

39. Kaufhold N, Schaller SJ, Stäuble CG, et al. Sugammadex and neostigmine dose-finding study for reversal of residual neuromuscular block at a train-of-four ratio of 0.2 (SUNDRO20) †. Br J Anaesth. 2016;116(2): 233-240. 
40. Magorian TT, Lynam DP, Caldwell JE, Miller RD. Can early administration of neostigmine, in single or repeated doses, alter the course of neuromuscular recovery from a vecuronium-induced neuromuscular blockade? Anesthesiology. 1990;73(3):410-414.

41. McCourt KC, Mirakhur RK, Kerr CM. Dosage of neostigmine for reversal of rocuronium block from two levels of spontaneous recovery. Anaesthesia. 1999;54(7):651-655.

42. Lederer W, Reiner T, Khuenl-Brady KS. Neostigmine injected 5 minutes after low-dose rocuronium accelerates the recovery of neuromuscular function. J Clin Anesth. 2010;22(6):420-424.

43. Jones JE, Parker CJ, Hunter JM. Antagonism of blockade produced by atracurium or vecuronium with low doses of neostigmine. Br J Anaesth. 1988;61(5):560-564.

44. Schaller SJ, Fink H, Ulm K, Blobner M. Sugammadex and neostigmine dose-finding study for reversal of shallow residual neuromuscular block. Anesthesiology. 2010;113(5):1054-1060.

45. Fuchs-Buder T, Baumann C, De Guis J, Guerci P, Meistelman C. Lowdose neostigmine to antagonise shallow atracurium neuromuscular block during inhalational anaesthesia: a randomised controlled trial Eur J Anaesthesiol. 2013;30(10):594-598.

46. Eikermann M, Houle TT. Antagonism of neuromuscular block: all things are poison; only the dose makes a thing not a poison. Br J Anaesth. 2016;116(2):157-159.

47. McLean DJ, Diaz-Gil D, Farhan HN, Ladha KS, Kurth T, Eikermann M. Dose-dependent association between intermediateacting neuromuscular-blocking agents and postoperative respiratory complications. Anesthesiology. 2015;122(6):1201-1213.

48. Eikermann M, Fassbender P, Malhotra A, et al. Unwarranted administration of acetylcholinesterase inhibitors can impair genioglossus and diaphragm muscle function. Anesthesiology. 2007;107(4):621-629.

49. Kim KS, Cheong MA, Lee HJ, Lee JM. Tactile assessment for the reversibility of rocuronium-induced neuromuscular blockade during propofol or sevoflurane anesthesia. Anesth Analg. 2004;99(4):1080-1085.

50. Brull SJ, Naguib M. How to catch unicorns (and other fairytales) Anesthesiology. 2018;128(1):1-3.

51. Astley BA, Katz RL, Payne JP. Electrical and mechanical responses after neuromuscular blockade with vecuronium, and subsequent antagonism with neostigmine or edrophonium. Br J Anaesth. 1987;59(8) 983-988.

52. Caldwell JE. Reversal of residual neuromuscular block with neostigmine at one to four hours after a single intubating dose of vecuronium. Anesth Analg. 1995;80(6):1168-1174.

53. Eikermann M, Zaremba S, Malhotra A, Jordan AS, Rosow C, Chamberlin NL. Neostigmine but not sugammadex impairs upper airway dilator muscle activity and breathing. Br J Anaesth. 2008;101(3): 344-349.

54. Herbstreit F, Zigrahn D, Ochterbeck C, Peters J, Eikermann M. Neostigmine/glycopyrrolate administered after recovery from neuromuscular block increases upper airway collapsibility by decreasing genioglossus muscle activity in response to negative pharyngeal pressure. Anesthesiology. 2010;113(6):1280-1288.

55. Caldwell JE. Clinical limitations of acetylcholinesterase antagonists. J Crit Care. 2009;24(1):21-28.

56. Kirkegaard-Nielsen H, Helbo-Hansen HS, Lindholm P, Severinsen IK, Pedersen HS, Jensen EW. Optimum time for neostigmine reversal of atracurium-induced neuromuscular blockade. Can J Anaesth. 1996; 43(9):932-938.

57. Engbaek J, Ostergaard D, Skovgaard LT, Viby-Mogensen J. Reversal of intense neuromuscular blockade following infusion of atracurium. Anesthesiology. 1990;72(5):803-806.

58. Jones RK, Caldwell JE, Brull SJ, Soto RG. Reversal of profound rocuronium-induced blockade with sugammadex: a randomized comparison with neostigmine. Anesthesiology. 2008;109(5):816-824.

59. Lemmens HJ, El-Orbany MI, Berry J, Morte JB Jr, Martin G. Reversal of profound vecuronium-induced neuromuscular block under sevoflurane anesthesia: sugammadex versus neostigmine. BMC Anesthesiol. 2010; 10(15):15
60. Caldwell JE, Robertson EN, Baird WL. Antagonism of profound neuromuscular blockade induced by vecuronium or atracurium. Comparison of neostigmine with edrophonium. Br J Anaesth. 1986;58(11): 1285-1289.

61. Plaud B, Debaene B, Donati F, Marty J. Residual paralysis after emergence from anesthesia. Anesthesiology. 2010;112(4):1013-1022.

62. Tajaate N, Schreiber JU, Fuchs-Buder T, Jelting Y, Kranke P. Neostigminebased reversal of intermediate acting neuromuscular blocking agents to prevent postoperative residual paralysis: A systematic review. Eur J Anaesthesiol. 2018;35(3):184-192.

63. Dubovoy T, Housey M, Devine S, Kheterpal S. Observational study on patterns of neuromuscular blockade reversal. BMC Anesthesiol. 2016; 16(1): 103 .

64. Hristovska AM, Duch P, Allingstrup M, Afshari A. Efficacy and safety of sugammadex versus neostigmine in reversing neuromuscular blockade in adults. Cochrane Database Syst Rev. 2017;8:CD012763.

65. Song IA, Seo KS, Oh AY, et al. Timing of reversal with respect to three nerve stimulator end-points from cisatracurium-induced neuromuscular block. Anaesthesia. 2015;70(7):797-802.

66. Fox MA, Keens SJ, Utting JE. Neostigmine in the antagonism of the action of atracurium. Br J Anaesth. 1987;59(4):468-472.

67. Ostheimer GW. A comparison of glycopyrrolate and atropine during reversal of nondepolarizing neuromuscular block with neostigmine. Anesth Analg. 1977;56(2):182-186.

68. Tramèr MR, Fuchs-Buder T. Omitting antagonism of neuromuscular block: effect on postoperative nausea and vomiting and risk of residual paralysis. A systematic review. Br J Anaesth. 1999;82(3):379-386.

69. Abad-Gurumeta A, Ripollés-Melchor J, Casans-Francés R, et al. A systematic review of sugammadex vs neostigmine for reversal of neuromuscular blockade. Anaesthesia. 2015;70(12):1441-1452.

70. Cheng CR, Sessler DI, Apfel CC. Does neostigmine administration produce a clinically important increase in postoperative nausea and vomiting? Anesth Analg. 2005;101(5):1349-1355.

71. Murphy GS, Szokol JW, Avram MJ, et al. Residual neuromuscular block in the elderly: incidence and clinical implications. Anesthesiology. 2015;123(6):1322-1336

72. Young WL, Matteo RS, Ornstein E. Duration of action of neostigmine and pyridostigmine in the elderly. Anesth Analg. 1988;67(8): $775-778$.

73. Cope TM, Hunter JM. Selecting neuromuscular-blocking drugs for elderly patients. Drugs Aging. 2003;20(2):125-140.

74. Marsh RH, Chmielewski AT, Goat VA. Recovery from pancuronium. A comparison between old and young patients. Anaesthesia. 1980; 35(12):1193-1196.

75. Young WL, Backus W, Matteo RS, Ornstein E, Diaz J. Pharmacokinetics and pharmacodynamics of neostigmine in the elderly [abstract]. Anesthesiology. 1984;61(3A):A300.

76. Chmielewski AT, Loach AB, Goat VA. Recovery from neuromuscular blockade. A comparison between old and young patients. Anaesthesia. 1978;33(6):539-542.

77. Koscielniak-Nielsen ZJ, Law-Min JC, Donati F, Bevan DR, Clement P, Wise R. Dose-response relations of doxacurium and its reversal with neostigmine in young adults and healthy elderly patients. Anesth Analg. 1992;74(6):845-850.

78. McCarthy GJ, Cooper R, Stanley JC, Mirakhur RK. Dose-response relationships for neostigmine antagonism of vecuronium-induced neuromuscular block in adults and the elderly. Br J Anaesth. 1992;69(3): 281-283.

79. Muravchick S, Owens WD, Felts JA. Glycopyrrolate and cardiac dysrhythmias in geriatric patients after reversal of neuromuscular blockade. Can Anaesth Soc J. 1979;26(1):22-25.

80. Owens WD, Waldbaum LS, Stephen CR. Cardiac dysrhythmia following reversal of neuromuscular blocking agents in geriatric patients. Anesth Analg. 1978;57(2):186-190.

81. Mirakhur RK. Antagonism of neuromuscular block in the elderly. A comparison of atropine and glycopyrronium in a mixture with neostigmine. Anaesthesia. 1985;40(3):254-258. 
82. Ledowski T, O’Dea B, Meyerkort L, Hegarty M, Von Ungern-Sternberg BS. Postoperative residual neuromuscular paralysis at an Australian tertiary children's hospital. Anesthesiol Res Pract. 2015;2015:410248.

83. Cook DR. Muscle relaxants in infants and children. Anesth Analg. 1981;60(5):335-343.

84. Bush GH, Stead AL. The use of d-tubocurarine in neonatal anaesthesia. Br J Anaesth. 1962;34:721-728.

85. Fisher DM, Cronnelly R, Miller RD, Sharma M. The neuromuscular pharmacology of neostigmine in infants and children. Anesthesiology. 1983;59(3):220-225.

86. Bevan JC, Purday JP, Reimer EJ, Bevan DR. Reversal of doxacurium and pancuronium neuromuscular blockade with neostigmine in children. Can J Anaesth. 1994;41(11):1074-1080.

87. Abdulatif M, Mowafi H, Al-Ghamdi A, El-Sanabary M. Dose-response relationships for neostigmine antagonism of rocuronium-induced neuromuscular block in children and adults. Br J Anaesth. 1996;77(6): $710-715$.

88. Meakin G, Sweet PT, Bevan JC, Bevan DR. Neostigmine and edrophonium as antagonists of pancuronium in infants and children. Anesthesiology. 1983;59(4):316-321.

89. Gwinnutt CL, Walker RW, Meakin G. Antagonism of intense atracurium-induced neuromuscular block in children. $\mathrm{Br} J$ Anaesth. 1991;67(1):13-16.
90. Black GW, Mirakhur RK, Keilty SR, Love SH. Reversal of nondepolarising neuromuscular block in children: a comparison of atropine and glycopyrrolate in a mixture with neostigmine. Anaesthesia. 1980;35(9):913-916.

91. Debaene B, Meistelman C, D'Hollander A. Recovery from vecuronium neuromuscular blockade following neostigmine administration in infants, children, and adults during halothane anesthesia. Anesthesiology. 1989;71(6):840-844.

92. Motsch J, Leuwer M, Böttiger BW, Bach A, Schönstedt R, Martin E. Dose-response, time-course of action and recovery of rocuronium bromide in children during halothane anaesthesia. Eur J Anaesthesiol Suppl. 1995;11:73-78.

93. Liu J, Cheng Z. Comparison of neostigmine induced reversal of rocuronium in different age children. Zhonghua Yi Xue Za Zhi. 2016;96(10): 807-811.

94. Fisher DM, Cronnelly R, Sharma M, Miller RD. Clinical pharmacology of edrophonium in infants and children. Anesthesiology. 1984; 61(4):428-433.

95. Cook DR. Paediatric anaesthesia: pharmacological considerations. Drugs. 1976;12(3):212-221.

96. Yang L, Yang D, Li Q, Zuo Y, Lu D. Neostigmine for reversal of neuromuscular block in paediatric patients. Cochrane Database Syst Rev. 2014;5(5):CD010110.
Therapeutics and Clinical Risk Management

\section{Publish your work in this journal}

Therapeutics and Clinical Risk Management is an international, peerreviewed journal of clinical therapeutics and risk management, focusing on concise rapid reporting of clinical studies in all therapeutic areas outcomes, safety, and programs for the effective, safe, and sustained use of medicines. This journal is indexed on PubMed Central, CAS,

\section{Dovepress}

EMBase, Scopus and the Elsevier Bibliographic databases. The manuscript management system is completely online and includes a very quick and fair peer-review system, which is all easy to use. Visit http://www.dovepress.com/testimonials.php to read real quotes from published authors. 